\title{
Let's talk over coffee: Exploring the effect of coffee flavour descriptions on consumer imagery
} and behaviour

(1)

Bente Klein Hazebroek \& Ilja Croijmans

Faculty of Social and Behavioural Science, Utrecht University, The Netherlands

Faculty of Arts, Radboud University, Nijmegen, The Netherlands

Corresponding author: Correspondence concerning this article should be addressed to dr. Ilja Croijmans, i.croijmans@ru.nl 
Online, as offline, purchase decisions are based on expectations about flavour and taste, offering an opportunity to make healthy and sustainable options desirable by using the right descriptions. This study investigates the effect of different types of coffee flavour descriptions on consumers, showing language can influence consumer purchase behaviour. In two experiments, participants were asked to rate vividness of imagery, desire to taste, and willingness to pay for several coffee flavour descriptions online. In the first experiment, descriptions differed on the type of words used: abstract words ("sweet"), evaluative words ("nice"), source-based words ("berries"), or a combination of these. Word type had an effect on all three variables, with source-based terms leading to the most vivid imagery, highest desire to taste, and highest willingness to pay. In the second experiment, descriptions presented flavour words in different description contexts (a stative, sensory, or figurative description), or a simple summation of those 6 words. The results showed no difference between the different types of descriptions, but words in sentences led to higher imagery vividness, higher desire to taste, and higher willingness to pay. Together, this suggests consumers seem to be able to imagine flavour from a verbal description quite clearly, but it depends on the type of words used and the form in which these words are presented. The desire to taste and willingness to pay for a product relate to the degree of imageability. The results are not only useful for optimising (coffee) flavour descriptions, but also for shaping consumer choices.

Keywords: Coffee, Flavour, Consumer behaviour, Imagery, Sensory marketing, Language 


\section{Introduction}

Clothing, gadgets, furniture, home accessories, and groceries: consumers more often take to the internet for their purchases. The ease of online shopping increases, yet, the options to inform customers via a smartphone or computer screen are limited. A photo or video of, for example a t-shirt, couch or a camera can be shown online, and measurements are specified in text, but it is impossible to capture and transmit olfactory, gustatory, and tactile sensations of products, such as perfume, food, and beverages, online. This makes sensory marketing difficult in these domains. Humans can express and communicate about sensory observations in language, but can a consumer imagine the smell of perfume, taste of food, or feel of a fabric from a verbal description? Especially in a time where online shopping seems to be the standard, it is necessary to understand if and how sensory product information can be communicated to consumers, and how language can shape desire for a product.

The perception of product information in any sensory domain is multi-dimensional: consumers go through a cognitive, affective, and behavioural phase, in which product information is transmitted, emotion induced, and action taken, respectively (Hernik, 2013, as discussed in Wyrwa \& Barska, 2017). The theory of planned behaviour (Ajzen, 1991) proposes that behaviour stems from individual beliefs, which are shaped by attitude, subjective norms, and perceived control. The aim of product information is therefore not only to inform, but also to persuade consumers to buy it through promoting the product on an emotional level, by increasing the desire for a product. Marketeers thus provide consumers with various textual cues that influence product judgement and decision making (Creusen \& Schoormans, 2005; Schifferstein et al., 2013). As flavour is an important deciding factor in food consumption (Clark, 1998; Boesveldt \& De Graaf, 2017; Boesveldt et al., 2018; Boesveldt \& Parma, 2021), appetitive cues are relevant when evoking the desire to taste a product.

Most people are able to recognise a flavour in a given context, but find it difficult to vividly imagine a smell or taste without gustatory or olfactory input, while visual, auditory or tactile images seem relatively easy to form (Andrade et al., 2014; Arshamian \& Larsson, 2014; Arshamian et al., 2020). Language can still engage and activate simulations for flavours. According to grounded cognition theory (see Barsalou, 2008), knowledge is not coded as semantic memory, but rather 
emerges from perception, action, and introspection. Humans receive information about their surroundings through their senses and shape what they perceive through individual goals and beliefs, so cognitive processes are thought to be embodied in sensory experience. In this view, mental imagery is the volitional act of simulating sensory perception from perceptual memories. Sensory marketing draws on the grounded cognition theory of desire, and is defined as "marketing that engages the consumers' senses and affects their perception, judgement and behaviour" (Krishna et al., 2016, p. 142). To understand a verbal flavour description, the experience of smelling, eating or drinking is thus simulated to retrieve meaning of the words (Barsalou, 2008; Papies et al., 2020). Since word meaning is thought to be embodied in, and derives from, sensory experience (Barsalou, 1999; Meteyard et al., 2012), grounded cognition theory implies that verbal communication is successful in transmitting sensory product information, by employing mental simulation to understand language.

Flavour descriptions can impact consumer behaviour, and sensory descriptions are among the most important attributes consumers base their purchase decisions on in choice experiments (Jürkenbeck \& Spiller, 2021). Research for example shows that highly desirable food is more likely to be described using eating-simulation features, whereas more neutral appreciated food is described using the visual appearance (Papies, 2013). Papies and colleagues (2020) explain this by the fact that humans engage with food in multidimensional settings, and thus remember (positive) associations with the whole experience of food consumption. Language that refers to eating simulations gives an expectation of what food will taste like, and therefore triggers desire, whereas language that refers to visual properties does not (Turnwald \& Crum, 2019; Papies et al., 2020). Such rewarding, multisensory simulation evoking language could be used to persuade consumers to choose healthier, more sustainable products, for example plant-based proteins instead of animal sourced proteins (e.g., Willett et al., 2019).

Although olfactory and gustatory imagery are poor, and smell and taste vocabulary limited in many languages (Majid et al., 2018), such studies illustrate that flavour experience can be derived from other senses than smell and taste as well, meaning that information from other sensory domains can be used to construct a mental flavour image. Speed and Majid (2020) argue that "the language of the lower senses [i.e. smell, taste, touch] could be crossmodally grounded to compensate for reduced 
simulation" (p. 381). Furthermore, figurative language makes it possible to map linguistic information from one domain that is known, to another domain that is unknown (Glucksberg, 2003), i.e. flavour in this case. Glucksberg (2003) explains that metaphors are processed automatically, and just as fast as literal text, so it seems that marketeers can choose to use both literal and figurative language to evoke a mental flavour image.

Multisensory language is used in descriptions of wine, usually in a set manner, describing aspects of the colour, smell, flavour, and aftertaste in that order (Herdenstam et al., 2009; Croijmans et al., 2020). In these so called wine reviews or tasting notes, metaphors are often successfully used to sketch a holistic description of the flavour of a wine (Paradis \& Eeg-Olofsson, 2013; Suárez-Toste, 2007; Suárez-Toste, 2017), and the structure is often in the form of some sort of narrative. The successful use of metaphors might be explained from a grounded cognition point of view, since metaphors automatically lead to mental simulation and are thus easy to understand (Glucksberg, 2003), which may even be true, through crossmodal simulation, for a target domain that is weakly embodied, such as olfaction and gustation (Speed \& Majid, 2017).

In contrast, for coffee, the structure of descriptions is usually less structured. On a bag of coffee beans in an online store or (specialty) coffee shop, flavour, origin, roast, and strength are usually secondary to branding, or objective information on the origin, sustainability and production method. The coffee's flavour is described in just a few words or sentences on the front of a package, or online in a textbox next to a photo of roasted beans. Descriptions are often a few tasting notes that compare the flavour to a different object (i.e., source-based language, e.g., 'vanilla, 'peach'), or abstract taste vocabulary ('sweet', 'acidity'). This reflects how coffee experts evaluate their coffee during so-called coffee cupping evaluations, as for example taught by the Specialty Coffee Association (SCA, 2022; Li, Streletskaya, \& Gomez, 2019). This may nevertheless not reflect how consumers understand the descriptions best. Evaluative words ('nice', 'disgusting') are not often used by coffee experts, although consumers tend to rely primarily on these to describe flavours (Croijmans \& Majid, 2016). If olfactory language activates broad, valenced concepts (Speed \& Majid, 2020; Muñoz-Vilches et al., 2020), evaluative language may be just as effective in driving product desire as 
source based language. In contrast, if there is some meaningful distinction in olfactory or flavour language to be made based on concreteness, more concrete language should be more effective in driving desire than abstract or evaluative language. Taken together, this overview shows the different ways in which flavours of coffee can be described: either using a few singular source-based, abstract, or evaluative terms, or using these words in a sentence structure, more similar to how wine experts review wine. Expanding on the latter contrast, work has shown that words in sentence context are much more effective at engaging mental simulation than singular verbs, in that case (Bergen et al., 2007). Following from this, sentence structured descriptions would be more effective at informing and persuading consumers who intend to purchase flavoured products online.

To meet with consumer expectations, it is necessary to provide information they can understand (cf. Krishna, 2012; Elder \& Krishna, 2010; Krishna \& Schwarz, 2014). Thus, in order to investigate the communicative success of flavour descriptions on coffee packaging for regular coffee consumers, this research explored different description strategies on consumer behaviour. There is little research on how words can affect the consumer's desire and choice. The main question that this research aims to answer is: "Can the purchase intention for coffee, as measured by the desire to taste, and willingness to pay, be affected by a verbal description?" In addition, we seek to explore whether the imagery that the description evokes is related to desire to taste and/or willingness to pay.

To answer these questions about consumers' understanding of flavour descriptions, two separate online experiments were conducted. Experiment A explored the role of the type of words, i.e., abstract words, source-based words, evaluative words (following Majid \& Burenhult, 2014), or a combination of these, used to describe coffee flavours, presented without the context of a full narrative description. In Experiment B we examined whether presenting words in the context of a few sentences may provide an additional benefit for consumers' understanding of the flavour, and their subsequent behaviour. 
In this first experiment, the type of words used to describe a coffee flavour is manipulated. The experiment was an online survey with a within-subjects design, was available on any computer or smartphone connected to the internet, and lasted approximately fifteen minutes. Both experiments were pre-registered at the Open Science Framework (https://osf.io/wd8nf/), and the methods were approved by the Utrecht University Ethics Review Board of the Faculty of Social \& Behavioural Sciences under registration number 21-0852.

\section{Participants}

Fenko, and colleagues (2018) found that text on packaging significantly influences purchase intention with a medium effect size. Based on this, we performed a power analysis (power $=.9, p<.05, \eta^{2}=$ .12), which indicated a minimum sample size of 27 participants for the current experiment. To ensure having enough usable data, a total of 40 British participants (13 male, 26 female, 1 preferred not to say), aged 19-67 years $(M=34, S D=12)$ was recruited via online participant recruitment Prolific. Native language shapes thought and coding of the senses (Majid et al., 2018; Speed \& Majid, 2020), so only participants with United Kingdom nationality were invited to take part in this study to avoid a linguistic barrier. All participants reported that they were residents of the United Kingdom, that their primary language was English, and that they were regular coffee consumers, i.e. regularly buy coffee beans from the supermarket to consume at home at least a few times a year. Self-reported coffee expertise (measured using a modified Self-rated Wine Expertise Questionnaire by Johnson \& Bastian, 2007, see Appendix C) ranges from 1.6-8 (scale 1-9, $M=5.56, S D=1.73$ ). Self-reported coffee imagery vividness, measured using a short, 6-item questionnaire based on the Vividness of Wine Imagery Questionnaire (Croijmans, Speed, Arshamian \& Majid, 2019; see Appendix B), ranges from 2.5-5 (scale 1-5, $M=4.14, S D=0.66)$, with smell having the highest imageability $(M=4.30, S D=$ $.68)$, followed by feel $(M=4.06, S D=.81)$, and taste $(M=4.05, S D=.78)$. Participants reported to, on average, pay $8.66 \mathrm{GBP}(S D=3.85)$ for 500 grams of coffee beans. Informed consent was given by all participants, and everyone received a compensation of 2.50 GBP.

\section{Items}


Five coffee profiles were created in English, all including three source-based, three abstract and three evaluative flavour words. The profiles are mainly based on Dutch descriptions given by coffee experts after tasting five different coffees (28/45: 10 source-based, 12 abstract, 6 evaluative, see Croijmans \& Majid, 2016), supplemented with words from the Coffee Taster's Flavour Wheel (8/45: 5 sourcebased, 3 abstract, see Spencer et al., 2016) and words that large Dutch coffee brands use on their packaging, translated to English (9/45: 9 evaluative). Here, source-based words are nouns that refer to an object or other well-defined source; abstract words are adjectives that may be derived from a source, but are widely applicable across domains; and evaluative words are subjective adjectives. All words are checked for their level of concreteness, using concreteness ratings on a scale from 1-5 from Brysbaert, and colleagues (2014). All source-based words have a mean concreteness rating between 4.5-5, abstract words have a mean concreteness rating between $2-4$, and evaluative words have a mean concreteness rating between 1.5-2.5.

For each of the five fictional coffee descriptions, there are four conditions in which they could be presented: only source-based words; only abstract words; only evaluative words; or a combination of a source-based, abstract and evaluative word. All 20 descriptions can be found in Table 1.

Coffee Flavour Descriptions Experiment A.

\begin{tabular}{|c|c|c|c|c|c|}
\hline & Coffee 1 & Coffee 2 & Coffee 3 & Coffee 4 & Coffee 5 \\
\hline Source-based & $\begin{array}{l}\text { honey } \\
\text { chocolate } \\
\text { pear }\end{array}$ & $\begin{array}{l}\text { blueberry } \\
\text { caramel } \\
\text { almond }\end{array}$ & $\begin{array}{c}\text { apple } \\
\text { lemon } \\
\text { caramel }\end{array}$ & $\begin{array}{l}\text { chocolate } \\
\text { peanut } \\
\text { flowers }\end{array}$ & $\begin{array}{l}\text { vanillh89 } \\
\text { orange } \\
\text { berry }\end{array}$ \\
\hline Abstract & $\begin{array}{l}\text { sweet } \\
\text { acidic } \\
\text { mild }\end{array}$ & $\begin{array}{c}\text { balanced } \\
\text { woody } \\
\text { sweet }\end{array}$ & $\begin{array}{l}\text { volatile } \\
\text { acidic } \\
\text { fruity }\end{array}$ & $\begin{array}{c}\text { floral } \\
\text { balanced } \\
\text { soft }\end{array}$ & $\begin{array}{l}\text { creamig1 } \\
\text { sweet } 92 \\
\text { smooth }\end{array}$ \\
\hline Evaluative & $\begin{array}{l}\text { exciting } \\
\text { distinct } \\
\text { appealing }\end{array}$ & $\begin{array}{l}\text { pleasant } \\
\text { exciting } \\
\text { lovely }\end{array}$ & $\begin{array}{l}\text { delicate } \\
\text { refreshing } \\
\text { pleasant }\end{array}$ & $\begin{array}{c}\text { exquisite } \\
\text { pleasant } \\
\text { wonderful }\end{array}$ & $\begin{array}{c}\text { delightfưl } \\
\text { interestingy } \\
\text { extraordinary }\end{array}$ \\
\hline Combination & $\begin{array}{l}\text { honey } \\
\text { sweet } \\
\text { exciting }\end{array}$ & $\begin{array}{l}\text { blueberry } \\
\text { balanced } \\
\text { pleasant }\end{array}$ & $\begin{array}{l}\text { caramel } \\
\text { fruity } \\
\text { delicate }\end{array}$ & $\begin{array}{l}\text { chocolate } \\
\text { floral } \\
\text { exquisite }\end{array}$ & $\begin{array}{l}\text { orange } \\
\text { creamy96 } \\
\text { extraordinary }\end{array}$ \\
\hline
\end{tabular}


The coffee descriptions were presented in an imitation of an online store interface. This image includes a picture of a bag of coffee beans, with the coffee's flavour description next to it. The buttons 'choose grind', 'size', 'quantity' and 'add to cart' make it look like a real interface, but were not interactive. This layout was the same for all 20 items; only the flavour descriptions were manipulated. See the Appendix A for a screenshot of the online experiment.

\section{Procedure}

Participants received a link to an online survey and could conduct the experiment at any time and place. Before answering the experimental questions, all participants filled out how much they are usually willing to pay for coffee from the supermarket. Next, the 20 items were given in a random order. Everyone answered the following three questions about each item, which were displayed directly underneath an image (see Appendix A):

1. Vividness of imagery: 'Can you imagine the flavour of this coffee?' (scale 1-5)

2. Desire to taste: 'Would you like to try this coffee?' (scale 1-5)

3. Willingness to pay: 'How much are you willing to pay for a bag of 500 grams of this coffee?' (slider $£ 0$ - $£ 50$ )

This set of questions was based to selectively test specific aspects of purchase behavior outlined by the theory of planned behaviour (Ajzen, 1991), with desire to taste operationalising the behavioural attitude towards the product, and willingness to pay reflecting the actual behaviour. Imagery was added as this was hypothesised to affect both attitude and behaviour, as was for example suggested by Papies et al., (2020). Vividness of flavour imagery was a single question based on previous work investigating multisensory flavour imagery of wine (Croijmans et al., 2019; Croijmans \& Wang, 2021), which in turn was based on work on olfactory imagery (Gilbert, Crouch \& Kemp, 1998) and visual imagery (Marks, 1973).

After all the experimental questions were answered, participants were asked how often they buy coffee beans from the supermarket, and how often they drink coffee. They also filled out a self-reported vividness of coffee imagery questionnaire (based on the Vividness of Wine Imagery Questionnaire by 
Croijmans et al., 2019, Appendix B) and a short self-rated coffee expertise questionnaire based on Johnson \& Bastian (2007; see Appendix C). Descriptive statistics of these variables can be found in the Participants section.

\section{Data analysis}

As pre-registered, to understand what the influence of differential word use is on consumer cognition and behaviour, three repeated measures ANOVAs were done on the calculated average over trials of the three dependent measures (Vividness of imagery; Desire to taste; Willingness to pay), with description type as factor (4 levels: abstract; source-based; evaluative; combination). In case of significant main effects, Bonferroni corrected post-hoc pairwise comparisons (t-tests) were done. Next, the effects of self-reported coffee flavour imagery, coffee expertise, and coffee consumption on each of the repeated measures ANOVA models were checked using linear mixed effects regression modeling (LMER). To explore the effect of the cognitive factors Vividness of Imagery and Desire to Taste on the behavioral measure Willingness to Pay, LMER was done with Age as covariate.

The assumptions for the respective analyses were checked. Participants with values in the continuous dependent variable (Willingness to Pay) of more than 3 standard deviations from the mean were threated as outliers and removed. This resulted in 1 case being removed. Statistical analyses were performed using $\mathrm{R}$ ( $\mathrm{R}$ core team, 2021). The pre-registration, data, and R-markdown analysis file can be accessed at the Open Science Framework repository, https://osf.io/wd8nf/.

\section{Results Experiment A}

The test of normality (Kolmogorov-Smirnov and Shapiro-Wilk test) suggested the data violated the assumption of normality. Inspection of the Q-Q plot of the residuals suggested the distribution of the data showed a slight right skew. Based on Berkovits, Hancock and Nevitt (2000), stating that the analysis is relatively robust to violations of normality given relatively large sample sizes for a withinsubjects design, the data-analysis was carried out as planned. In addition, deviating from the preregistered analysis, it was decided to confirm the analyses in case of non-normal data using 
250

251

252

253

254

255

256

257

Friedman's non-parametric tests and Wilcoxon's signed-rank tests after performing the planned analyses.

Using an ANOVA with Greenhouse-Geisser sphericity correction, the analysis indicated that Type of Description significantly influenced Vividness of Imagery for the described coffee, $F(1.75,66.60)=$ 42.92, $p<.001, \eta_{\mathrm{p}}{ }^{2}=.53$; the Desire to Taste the described coffee, $F(1.83,69.57)=7.92, p=.001, \eta_{\mathrm{p}}{ }^{2}$ $=.17$; and Willingness to Pay for the described coffee, $F(1.79,68.17)=10.62, p<.001, \eta_{\mathrm{p}}{ }^{2}=.22$. The distribution of answers for each variable per description type are shown in Figure 1. This pattern of main effects was confirmed using Friedman's non-parametric tests.

Vividness of imagery

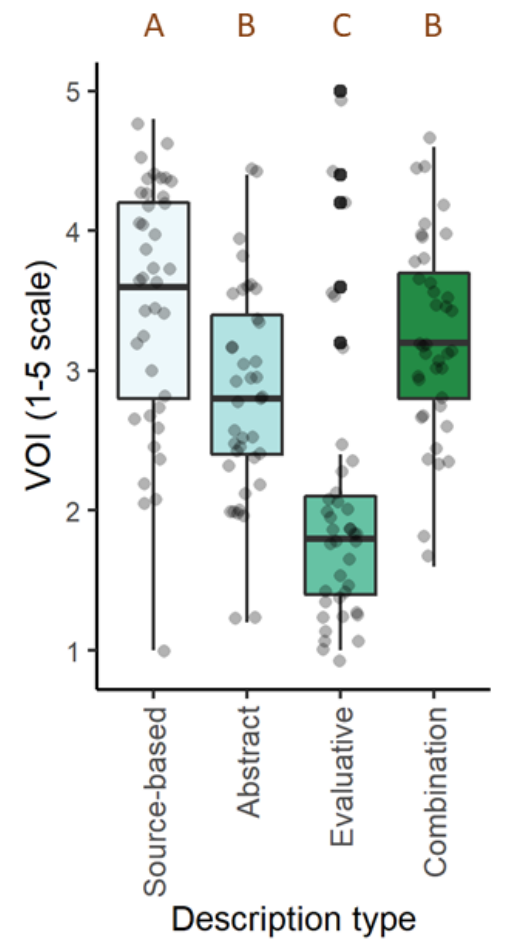

Desire to taste

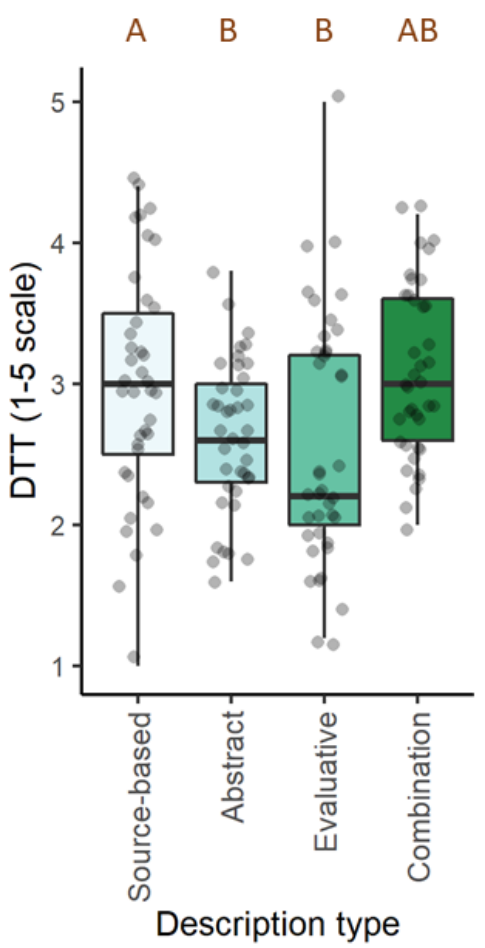

Willingness to pay

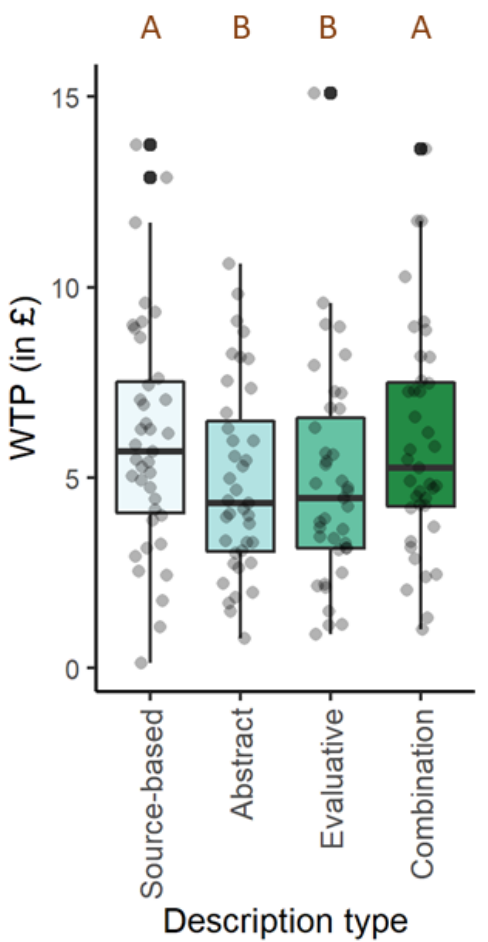

Figure 1. Box-and-whisker plots for the averaged ratings per description type (abstract words, a combination of different word types, evaluative words, and source based words) for Vividness $O f$ Imagery (VOI), Desire To Taste (DTT), and Willingness To Pay (WTP). Letters above each boxplot indicate differences between means within each dependent variable: different letters indicate the means are statistically different (see text). Note. Box-and-whisker plots display the median and 1st and $3 r d$ quartiles ranges, and whiskers indicate range of the data. Grey dots denote individual data points. 
For Vividness of Imagery, post hoc pairwise comparisons using Bonferroni corrected t-tests

demonstrate significant differences between abstract and combined $(p<.01)$, abstract and evaluative $(p<.001)$, abstract and source-based $(p<.001)$, combined and evaluative $(p<.001)$, and evaluative and source-based $(p<.001)$ descriptions. For Desire to Taste, significant differences were found between abstract and combined $(p<.001)$, abstract and source-based $(p<.05)$, and combined and evaluative $(p<.01)$ descriptions. For Willingness to Pay, significant differences between abstract and combined $(p<.001)$, abstract and source-based $(p<.001)$, combined and evaluative $(p<.01)$, and evaluative and source-based $(p<.05)$ descriptions were found. Means and standard deviations for each dependent variable for each condition can be found in Table 1 . This pattern of results was confirmed using Wilcoxon's signed-rank tests.

\begin{tabular}{|c|c|c|c|c|}
\hline & $\begin{array}{l}\text { Number of } \\
\text { participants }\end{array}$ & $\begin{array}{l}\text { Vividness of } \\
\text { Imagery }\end{array}$ & Desire to Taste & $\begin{array}{l}\text { Willingness to Pay } \\
\text { (in GBP) }\end{array}$ \\
\hline Abstract terms & $n=39$ & $\begin{array}{l}M=2.83(S D= \\
.76)\end{array}$ & $M=2.63(S D=.54)$ & $\begin{array}{l}M=4.92(S D= \\
2.52)\end{array}$ \\
\hline Combination & $n=39$ & $\begin{array}{l}M=3.24(S D= \\
.70)\end{array}$ & $M=3.09(S D=.61)$ & $\begin{array}{l}M=5.91(S D= \\
2.94)\end{array}$ \\
\hline Evaluative terms & $n=39$ & $\begin{array}{l}M=2.00(S D= \\
.98)\end{array}$ & $M=2.57(S D=.89)$ & $\begin{array}{l}M=4.91(S D= \\
2.85)\end{array}$ \\
\hline Source-based terms & $n=39$ & $\begin{array}{l}M=3.49(S D= \\
.89)\end{array}$ & $M=2.99(S D=.82)$ & $\begin{array}{l}M=6.04(S D= \\
3.04)\end{array}$ \\
\hline
\end{tabular}

Table 1: Means and standard deviations (in brackets) for each of the dependent variables (Vividness of Imagery, Desire to Taste, and Willingness to Pay) across the four description conditions (abstract, source-based, evaluative, and combination) for Experiment A.

The follow-up LMER analysis showed Vividness of Imagery was not significantly influenced by Self-Reported Imagery $(p>.05)$ and Self-Reported Expertise $(p>.05)$, but was influenced by Frequency of Drinking Coffee $(p<.05)$. Drinking one more coffee per day increased Vividness of Imagery by $0.35(\mathrm{SE}=0.15)$. Neither of these variables had an effect on Desire to Taste and Willingness to Pay.

Next, an LMER analysis was done to test the influence of Vividness of Imagery (VOI) and Desire to Taste (DTT) on Willingness to Pay (WTP). The analysis indicated VOI was significantly 
related to WTP, with WTP increasing with $.50 \mathrm{GBP}(\mathrm{SE}=.06)$ for each point increase in VOI, $p<$ .001. DTT was also related to WTP, with WTP increasing with .86 GBP for each point increase in DTT, $p<.001$. The covariate Age was not related to WTP, $p=.19$.

To summarise, these results suggest that the vividness of imagery and desire to taste affect the willingness to pay for coffee, and that these in turn are influenced by the descriptions of those coffees. Coffee flavours can best be imagined from a concrete verbal description: both source-based words and a combination of a source-based, abstract, and evaluative word were rated with a significantly higher vividness of imagery, desire to taste, and willingness to pay, than abstract and evaluative descriptions. The type of description specifically had a large effect on vividness of imagery. More concrete, i.e. more informative, descriptions, seem most helpful for regular coffee consumers to form a mental image of a coffee's flavour, which might positively affect willingness to pay.

The results illustrate that consumers are able to imagine concrete flavour words most vividly. In this experiment, the descriptions were not presented in a sentence or accompanied by any other information, so the question that is asked next, is: does it matter in what context the words are placed? Danner and colleagues (2017) found that reading more elaborate descriptions on wine labels prior to tasting the wine evoked more positive emotional response profiles, and increased wine liking and willingness to pay, compared to a blind tasting or reading basic information beforehand.

Participants wanted to pay more for a bottle of wine with information about quality, origin, and a vivid sensory description. Wine bottles with expert ratings or a flavour description are also found to be preferred and desired more over bottles without such a label (Ribeiro et al., 2020; Croijmans \& Wang, 2021). Bergen and colleagues (2007) showed sentences lead to more vivid imagery than single words, and this strategy is often used by wine tasters to express flavour using sensory narratives. Metaphors are also frequently added (Paradis \& Eeg-Olofsson, 2013). These metaphors go beyond the olfactory and gustatory domain: sensory narratives usually include the four sensory experiences of vision, smell, touch, and taste, in this particular order, followed by an holistic experience of drinking the wine. Such reviews follow the order of the whole tasting procedure to emphasise the multi-sensory drinking experience. As mentioned before, figurative language may enhance vividness of an image and the 
desire to taste by mapping unknown information on a known source, possibly in another domain (Glucksberg, 2003). In the second experiment, the linguistic context (single terms vs. narratives) in which coffee flavours are presented is investigated, and whether any of these strategies (a stative, sensory or figurative narrative) help coffee consumers to form an image of a coffee flavour, and how this affects their subsequent behaviour.

\section{Methods Experiment B}

Similar to Experiment A, this experiment is a within-subjects design in the form of an online survey, lasted approximately fifteen minutes, and was available on any computer or smartphone connected to the internet.

\section{Participants}

Seventy British participants were recruited via online participant recruitment Prolific. To ensure having enough reliable data, this is more than the aim of 40 participants in Experiment A (participants could not be pre-screened for being a regular coffee consumer; which was a pre-requisite for participation). Participants that already participated in Experiment A were excluded from taking part. As in Experiment A, only participants with the United Kingdom nationality were allowed to take part in this experiment via Prolific. The participants reported that they were residents of the United Kingdom, six participants were non-native speakers of English (2 Greek, 1 Russian, 1 Armenian, 1 Chinese, 1 Dari), but reported to understand English at a near-native level. Four participants reported that they never bought coffee beans from the supermarket, and were excluded from further analysis. For the remaining 66 participants (22 male, 41 female, 1 non-binary, 2 preferred not to say), 18-62 years old $(M=33.8, S D=11.4)$, self-reported coffee expertise ranges from 1.4-9 (scale 1-9, $M=5.36$, $S D=1.68)$, and self-reported coffee imagery from $1.5-5$ (scale $1-5, M=3.80, S D=0.68$ ), in the order of feel $(M=3.94, S D=.79)$, smell $(M=3.81, S D=.84)$, and taste $(M=3.66, S D=.88)$. The participants reported to usually pay $7.96 \mathrm{GBP}$ on average $(S D=3.76)$ for 500 grams of coffee beans in the supermarket. Informed consent was given by all participants, and everyone received a compensation of $2.50 \mathrm{GBP}$. 


\section{Items}

340 The five coffee profiles that were created for Experiment A were used again to make the items for the

341 current experiment (see Table 2). From Experiment A, it appears that source-based descriptions and a

342 combination of different types of words can be imagined most vividly. As there are no major

343 difference between these conditions, and a combination of nouns and adjectives works well in

344 sentences, a fixed combination of two source-based, two abstract and two evaluative words was

345 chosen from each profile. For all coffees, one of the abstract words refers to aroma, the other to

346 mouthfeel. These six words were either presented on their own; in a stative description (adding a

347 minimum number of words to make proper sentences); in a sensory description (story that follows the

348 procedure of drinking coffee, i.e. order of smelling, tasting, feeling, evaluating); or in a figurative

349 description (making an indirect reference to a situation that is not necessarily related to drinking

350 coffee). As in Experiment A, these descriptions were presented in the form of a non-interactive online

351 supermarket product interface, see Appendix A.

352

353 
Table 2

Coffee Flavour Descriptions Experiment $B$.

\begin{tabular}{|c|c|c|c|c|c|}
\hline & Coffee 1 & Coffee 2 & Coffee 3 & Coffee 4 & Coffee 5 \\
\hline $\begin{array}{c}\text { Flavour } \\
\text { words }\end{array}$ & $\begin{array}{l}\text { honey } \\
\text { chocolate } \\
\text { acidic } \\
\text { mild } \\
\text { exciting } \\
\text { distinct } \\
\end{array}$ & $\begin{array}{c}\text { blueberry } \\
\text { caramel } \\
\text { balanced } \\
\text { woody } \\
\text { pleasant } \\
\text { lovely } \\
\end{array}$ & $\begin{array}{l}\text { apple } \\
\text { lemon } \\
\text { volatile } \\
\text { fruity } \\
\text { delicate } \\
\text { refreshing }\end{array}$ & $\begin{array}{c}\text { peanut } \\
\text { flowers } \\
\text { soft } \\
\text { floral } \\
\text { exquisite } \\
\text { wonderful } \\
\end{array}$ & $\begin{array}{c}\text { vanilla } \\
\text { orange } \\
\text { creamy } \\
\text { sweet } \\
\text { delightful } \\
\text { interesting } \\
\end{array}$ \\
\hline $\begin{array}{c}\text { Stative } \\
\text { description }\end{array}$ & $\begin{array}{l}\text { Mild coffee with } \\
\text { distinct hints of } \\
\text { honey and } \\
\text { chocolate. This } \\
\text { exciting taste is } \\
\text { slightly acidic. }\end{array}$ & $\begin{array}{l}\text { Balanced coffee } \\
\text { with a pleasant } \\
\text { woody taste. This } \\
\text { lovely coffee } \\
\text { includes notes of } \\
\text { blueberry and } \\
\text { caramel. }\end{array}$ & $\begin{array}{l}\text { This refreshing } \\
\text { coffee contains the } \\
\text { fruity taste of } \\
\text { apple and lemon. } \\
\text { It is a delicate and } \\
\text { volatile coffee. }\end{array}$ & $\begin{array}{l}\text { A wonderful, soft } \\
\text { coffee with hints } \\
\text { of peanut. Notes } \\
\text { of flowers make } \\
\text { this an exquisite } \\
\text { floral coffee. }\end{array}$ & $\begin{array}{l}\text { Delightful sweet } \\
\text { coffee with vanilla } \\
\text { and orange. The } \\
\text { creamy texture } \\
\text { creates an } \\
\text { interesting coffee. }\end{array}$ \\
\hline $\begin{array}{c}\text { Sensory } \\
\text { description }\end{array}$ & $\begin{array}{l}\text { The smell of } \\
\text { honey and taste of } \\
\text { chocolate are } \\
\text { accompanied by } \\
\text { an acidic } \\
\text { mouthfeel. This } \\
\text { mild coffee is } \\
\text { distinct and } \\
\text { exciting. }\end{array}$ & $\begin{array}{c}\text { The smell of } \\
\text { caramel and taste } \\
\text { of blueberry are } \\
\text { accompanied by a } \\
\text { balanced } \\
\text { mouthfeel. This } \\
\text { woody coffee is } \\
\text { pleasant and } \\
\text { lovely. }\end{array}$ & $\begin{array}{l}\text { The smell of apple } \\
\text { and taste of lemon } \\
\text { are accompanied } \\
\text { by a volatile } \\
\text { mouthfeel. This } \\
\text { fruity coffee is } \\
\text { delicate and } \\
\text { refreshing. }\end{array}$ & $\begin{array}{l}\text { The smell of } \\
\text { flowers and taste } \\
\text { of peanut are } \\
\text { accompanied by a } \\
\text { soft mouthfeel. } \\
\text { This floral coffee } \\
\text { is exquisite and } \\
\text { wonderful. }\end{array}$ & $\begin{array}{c}\text { The smell of } \\
\text { orange and taste of } \\
\text { vanilla are } \\
\text { accompanied by a } \\
\text { creamy mouthfeel. } \\
\text { This sweet coffee } \\
\text { is delightful and } \\
\text { interesting. }\end{array}$ \\
\hline $\begin{array}{l}\text { Figurative } \\
\text { description }\end{array}$ & $\begin{array}{l}\text { Although this } \\
\text { coffee is mild, it } \\
\text { has a very exciting } \\
\text { touch. Hints of } \\
\text { honey take you to } \\
\text { the enchanting } \\
\text { taste of chocolate, } \\
\text { sprinkled with a } \\
\text { dash of acidity. } \\
\text { This distinct } \\
\text { coffee is a true } \\
\text { walk in } \\
\text { wonderland. }\end{array}$ & $\begin{array}{l}\text { A hug in a mug, is } \\
\text { what you can call } \\
\text { this lovely coffee. } \\
\text { Embrace the } \\
\text { pleasant woody } \\
\text { taste and notes of } \\
\text { blueberry and } \\
\text { caramel that caress } \\
\text { the tongue. Wrap } \\
\text { your hands around } \\
\text { a cup of this } \\
\text { perfectly balanced } \\
\text { coffee. }\end{array}$ & $\begin{array}{l}\text { This volatile } \\
\text { coffee is like a day } \\
\text { in spring. The } \\
\text { fruity combination } \\
\text { of apple and } \\
\text { lemon reminds } \\
\text { you of a refreshing } \\
\text { walk through a } \\
\text { delicate meadow } \\
\text { on a sunny } \\
\text { morning. }\end{array}$ & $\begin{array}{c}\text { The } \\
\text { wonderful combin } \\
\text { ation of flowers } \\
\text { and peanuts takes } \\
\text { you overseas. } \\
\text { With its exquisite } \\
\text { soft and floral } \\
\text { taste, a sip of } \\
\text { this coffee will } \\
\text { make you feel as if } \\
\text { you are traveling } \\
\text { somewhere far } \\
\text { away. }\end{array}$ & $\begin{array}{l}\text { This interesting, } \\
\text { creamy coffee is } \\
\text { full of sweetness, } \\
\text { and is a perfect } \\
\text { treat to yourself. } \\
\text { Take your time to } \\
\text { unwrap the tastes } \\
\text { of vanilla and } \\
\text { orange, and make } \\
\text { sure to enjoy this } \\
\text { delightful gift. }\end{array}$ \\
\hline
\end{tabular}




\section{Procedure}

359 The procedure was exactly the same as in Experiment A.

360

\section{Data-analysis}

The data-analysis followed the analyses in Experiment A: Repeated measures ANOVAs were done on the calculated average over trials of the three dependent measures (Vividness of Imagery; Desire to Taste; Willingness to Pay), with description type as factor (4 levels: figurative descriptions, sensory descriptions, stative descriptions, flavour words). One participant was removed from the analysis for the reason of their answers being more than 3 standard deviations from the average WTP.

\section{Results Experiment B}

Similar to Experiment A, the data was found to be non-normal, with a slight skew to the right. As in Experiment A, we decided to proceed as planned, with Friedman's and Wilcoxon's signed-rank tests to confirm the findings. Using an Analysis of Variance with Greenhouse-Geisser sphericity correction, the results indicate that Type of Description significantly influenced Vividness of Imagery [F(2.11, $\left.135.14)=16.94, p<.001, \eta_{\mathrm{p}}{ }^{2}=.21\right]$, Desire to Taste the described coffee $[F(2.62,167.99)=13.39, p$ $\left.<.001, \eta_{\mathrm{p}}{ }^{2}=.17\right]$, and Willingness to Pay $\left[F(2.57,164.39)=7.54, p<.001, \eta_{\mathrm{p}}{ }^{2}=.11\right]$. This pattern was confirmed using Friedman's tests. Figure 2 displays the distribution of the mean values for all three variables per description type. 

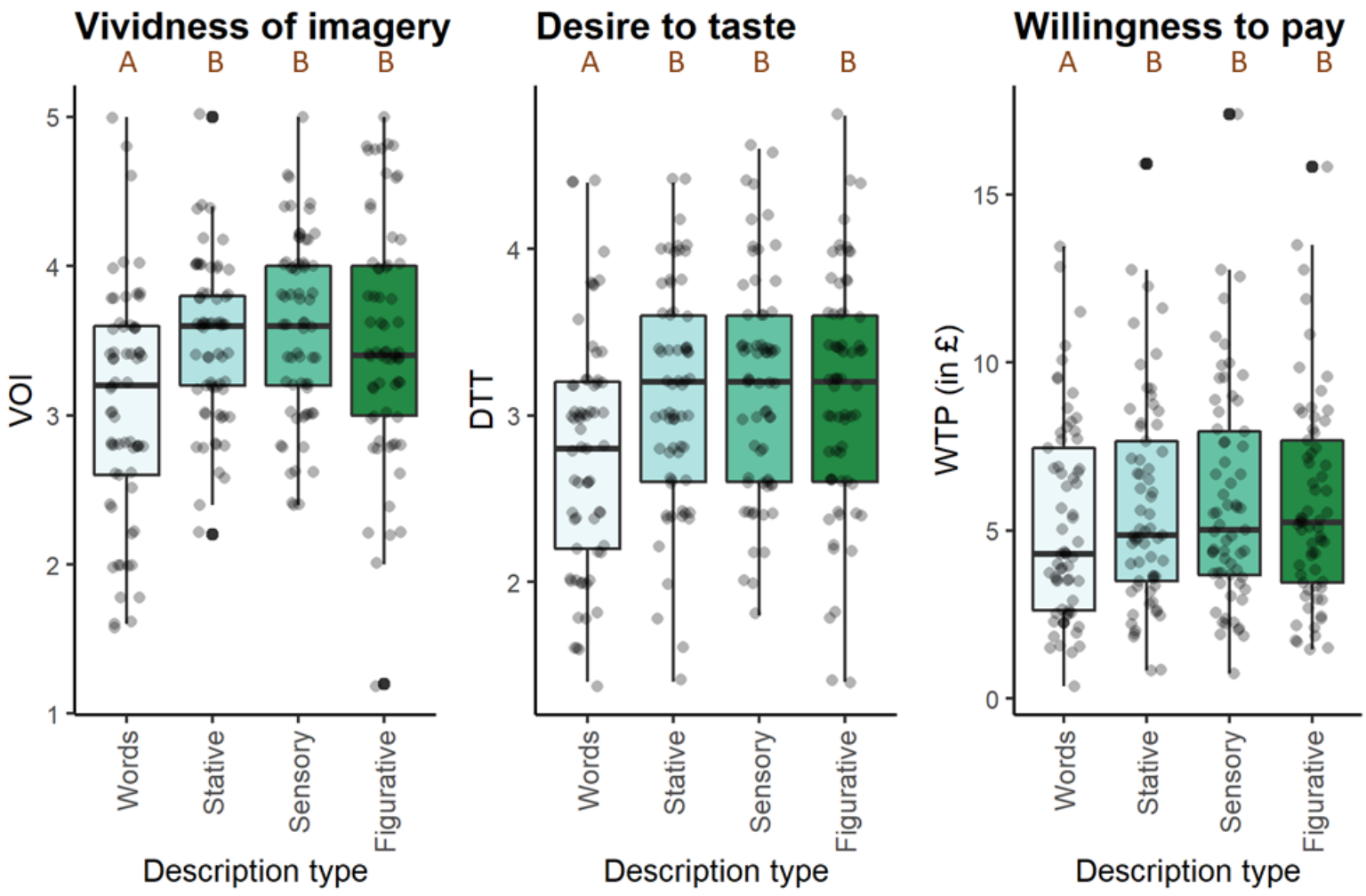

Figure 2. Box-and-whisker plots for the averaged ratings per description type (figurative narrative, sensory narrative, stative narrative, and flavour words) for vividness of imagery (VOI), desire to taste (DTT), and willingness to pay (WTP). Letters above each bar indicate differences between means within each dependent variable: different letters indicate the means are statistically different (see text). Note. Box-and-whisker plots display the median and 1st and 3rd quartiles ranges, and whiskers indicate range of the data. Grey dots denote individual data points.

For Vividness of Imagery, post hoc pairwise comparisons using Bonferroni corrected t-tests demonstrate significant differences between words and figurative $(p<.001)$, words and sensory $(p<$ $.001)$, and words and stative $(p<.001)$ descriptions. For Desire to Taste, the differences were also found to be significant between words and figurative $(p<.001)$, words and sensory $(p<.001)$, and words and stative $(p<.001)$ descriptions. For Willingness to Pay, again significant differences between words and figurative $(p<.05)$, words and sensory $(p<.01)$, and words and stative $(p<.05)$ descriptions were found. Ratings for all three variables have shown no significant differences between stative, sensory, 
and figurative descriptions (all $p>.05$ ). This pattern of results was confirmed using Wilcoxon's signedrank tests.

\begin{tabular}{|c|c|c|c|c|}
\hline & $\begin{array}{l}\text { Number of } \\
\text { participants }\end{array}$ & $\begin{array}{l}\text { Vividness of } \\
\text { Imagery }\end{array}$ & Desire to Taste & $\begin{array}{l}\text { Willingness to Pay } \\
\text { (in GBP) }\end{array}$ \\
\hline $\begin{array}{l}\text { Figurative } \\
\text { description }\end{array}$ & $n=65$ & $\begin{array}{l}M=3.51(S D= \\
.79)\end{array}$ & $\begin{array}{l}M=3.14(S D= \\
.71)\end{array}$ & $\begin{array}{l}M=5.78(S D= \\
3.08)\end{array}$ \\
\hline $\begin{array}{l}\text { Sensory } \\
\text { description }\end{array}$ & $n=65$ & $\begin{array}{l}M=3.59(S D= \\
.61)\end{array}$ & $\begin{array}{l}M=3.18(S D= \\
.66)\end{array}$ & $\begin{array}{l}M=5.89(S D= \\
3.25)\end{array}$ \\
\hline Stative description & $n=65$ & $\begin{array}{l}M=3.49(S D= \\
.53)\end{array}$ & $\begin{array}{l}M=3.12(S D= \\
.67)\end{array}$ & $\begin{array}{l}M=5.74(S D= \\
3.11)\end{array}$ \\
\hline Just words & $n=65$ & $\begin{array}{l}M=3.06(S D= \\
.77)\end{array}$ & $\begin{array}{l}M=2.78(S D= \\
.72)\end{array}$ & $\begin{array}{l}M=5.22(S D= \\
3.01)\end{array}$ \\
\hline
\end{tabular}

Table 2: Means and standard deviations (in brackets) for each of the dependent variables (Vividness of Imagery, Desire to Taste, and Willingness to Pay) across the four description conditions in Experiment B (figurative, sensory, stative, or just words).

The follow-up LMER analysis showed none of the variables in the model were significantly influenced by Self-Reported Imagery, Self-Reported Expertise or Frequency of Drinking Coffee (all $p>$ $.05)$.

To test the effects of Vividness of Imagery (VOI) and Desire to Taste (DTT) on Willingness to Pay (WTP), an LMER was done with Age as covariate. VOI predicted WTP, so that with each point increase in VOI, WTP increased with $.46(\mathrm{SE}=.052), p<.001$. Similarly, DTT was significantly related to WTP, with each point increase in DTT, WTP increases with $1.20(\mathrm{SE}=.044), p<.001$. As in Experiment A, Age was not related to WTP, $p=.999$.

Similar to Experiment A, a relation was found between the desire to taste and between the vividness of imagery and willingness to pay. This supports the hypothesis that a relationship between the ability to imagine flavours and consumption behaviour, as suggested by Experiment A. In addition, the results of Experiment B suggest that coffee flavours can be imagined more vividly when presented in a sentence or short narrative rather than using singular words: while there was no difference between stative, sensory, and figurative narratives, these conditions all differed significantly from isolated flavour words. All these narrative flavour descriptions also result in a higher desire to taste 
than the descriptions with only six words, and participants wanted to pay (slightly) more for these coffees as well. The results of this experiment imply that sentences are more informative than single words, as regular coffee consumers can form more vivid flavour images from elaborate descriptions.

\section{Discussion}

This study explored different coffee flavour descriptions and their effect on consumer behaviour, by asking regular coffee consumers to rate vividness of imagery, desire to taste, and willingness to pay after reading several verbal descriptions in a mock-up online setting. Consumers seem able to imagine a coffee flavour from a verbal description quite clearly, but it depends on the type of words used and the form in which these words are presented. Experiment A illustrates that concrete coffee flavour descriptions, as opposed to abstract or evaluative, can best be imagined, and result in both a higher desire to taste the described coffee and the willingness to pay for it. The correlation with imagery suggests the consumer's behaviour may be due to a higher imageability of those concrete descriptors. Results from Experiment B, in line with previous work (Bergen et al., 2007), show that narratives in any form (stative, sensory, figurative) are more helpful than only isolated words to construct a mental coffee flavour image, and confirm that there is a relation between vividness of imagery, desire to taste, and willingness to pay.

One possible explanation for the findings is that abstract, and especially evaluative, words are not concrete enough to form a vivid mental image: these words are adjectives that are widely applicable across domains and miss a reference to a specific source, so concreteness ratings are low for abstract and evaluative words (Brysbaert et al., 2014). Words such as 'pleasant' or 'exquisite' are useful in addition to other flavour words and make a narrative more vivid, but presumably are not informative enough presented on their own. Subjective experiences do not seem to capture specific smell or taste experiences of coffee flavour. Simonsen, and colleagues (2013) show that adjectives are less imageable than nouns and verbs, which could mean that, even if a participant rated his general coffee imagery to be relatively high, he could not vividly imagine a 'pleasant' flavour. Imagery is thought to be a simulation of perceptual experience that can be recalled with verbal cues (Barsalou, 1999; Barsalou, 2008; Meteyard et al., 2012), but apparently, abstract and evaluative words are not 
concrete enough to refer to a specific sensory percept, and presumably do not evoke a high desire to taste because of that.

In addition, participants were asked to rate vividness of imagery in general for each description trial, and not specifically olfactory or gustatory imagery. Perhaps the image of a 'lemon' flavour is more vivid than 'fruity', because a visual image of a lemon can be created more easily. The current study does not show in which sensory domain a flavour image was most vivid, although this information can be useful to optimise sensory marketing (in the coffee industry), both online and on physical packaging. Since especially olfactory and gustatory language concepts are weakly grounded, the rated vividness could indicate a crossmodal simulation, or a simulation on a coarse level, for example on the level of valence (cf. Speed \& Majid, 2017), which would indicate consumers merely imagined how much they liked the coffee without understanding how it would taste. At the same time, evaluative descriptions that map well onto the level of valence, were not rated highly imaginable. To understand what consumers imagine in different modalities more precisely, and to disentangle the relative contribution of different imagined modalities in consumer understanding of flavour description, imagery vividness could be assessed separately in different modalities (see e.g. Croijmans et al., 2019; Speed \& Majid, 2017; Speed \& Brysbaert, 2020).

The results of Experiment B suggest flavour descriptions are most effective when presented in a narrative format. Interestingly, even when the same words were used in different types of descriptions, words in sentence context lead to higher imagery vividness, but there was no difference in figurative versus stative description contexts. In the domain of motion, words in the context of an actual physical motion or a metaphorical motion were both shown to lead to similar eye-movement, suggesting both led to mental simulation (Castaño \& Carrol, 2020; also see Boulenger et al., 2009), which might explain the lack of a difference found in the current experiments. Summarising, in line with how wine experts generally describe the flavour of wine (Herdenstam et al., 2009), narratives seem more effective than single words to communicate flavours.

The results of this study are beneficial for marketeers that want to optimise online flavour descriptions or promote their brand, and simultaneously help consumers make a choice out of a broad 
range of products. Because aspects like self-reported imagery, level of coffee expertise, and frequency of drinking coffee may impact flavour imagery, it can be beneficial to tailor flavour descriptions to the knowledge and needs of several target groups. For example, experts have a (modest) domain-specific perceptual and linguistic advantage (Croijmans \& Majid, 2016), so they might prefer different product information than novices without training. Tailoring product information would be especially relevant and useful for online marketeers, because there is room for elaborate product descriptions online, consumer profiles can be available, and information can easily be adjusted and filtered. In addition, this research confirms flavour descriptions can increase how appetising food is when formulated properly (Speed et al., 2021), and may thus be able to persuade consumers to choose for more healthy, sustainable options, even when these options could come at a higher price.

This research knows a few limitations. First, the type of description had an effect on vividness of imagery, desire to taste, and willingness to pay, and although there is certainly a relation between these variables, it cannot be said that a more vivid flavour image directly leads to a higher payment. A possible reason is that participants could have simply rated how appealing a flavour description sounded, rather than rating the vividness of an olfactory or gustatory simulation. Previous research has indicated that people generally have poor mental imagery of smell and taste (e.g. Arshamian et al., 2020), thus it can be questioned to what extent vividness of imagery is an accurate assessment to measure verbal transmission of sensory product information. Second, the baseline price that participants indicated to normally pay for coffee was higher than the average price indicated in the experimental conditions. This could be due to the limited visual stimulation that the experiment offered: the visual appearance of products is crucial in consumer purchase processes. Future investigations should look take into account visual information, and could investigate the interaction between flavour descriptions and visual appearance, or other sensory information. Third, it must be noted that the results of this study do not necessarily apply to all languages in different cultural environments, since all participants were British and items were written in English. Language is a social and cultural human communication tool, and the coding of the senses differs among cultures 
and languages (Majid et al., 2018). Thus, specific cultural practices or experiences can influence flavour cognition and may yield different outcomes.

In conclusion, the language used to describe a flavour affects the transmission of information (vividness of imagery), as well as induced emotion (desire to taste) and consumer behaviour (willingness to pay). More concrete and vivid flavour descriptions seem to give consumers the best product expectation. When isolated, source-based words can be imagined most vividly, but evaluative and abstract words can be a useful addition to narratives to make a description more vivid and sound appealing. Coffee flavours can be communicated effectively to regular coffee consumers by choosing concrete and vivid language in sentences. It is proposed that future research should focus on different consumers' knowledge and needs when purchasing coffee beans, sensory domains that are simulated when creating a mental flavour image, and the possibility of combining verbal flavour descriptions with visual cues.

Both authors conceptualised the idea for this study. BKH created the methods and collected the data, and subsequently analysed the data and visualised the results, all under supervision of IC. BKH wrote the first version of the manuscript, with critical input from IC. IC revised the manuscript after receiving helpful comments from 2 anonymous reviewers.

\section{Acknowledgements}

The authors would like to thank the Specialty Coffee Association for inviting IC to the Sensory Summit 2020 in Zurich, the generous speaker's fee paid for this study. Additionally, we thank Christoph Strauch for his critical reading on the results. The authors declare no conflicts of interest. 
Ajzen, I. (1991). The theory of planned behavior. Organizational Behavior and Human Decision Processes, 50(2), 179-211.

Andrade, J., May, J., Deeprose, C., Baugh, S. J., \& Ganis, G. (2014). Assessing vividness of mental imagery: the Plymouth sensory imagery questionnaire. British Journal of Psychology, 105(4), 547563.

Arshamian, A., \& Larsson, M. (2014). Same same but different: the case of olfactory imagery. Frontiers in psychology, 5, 34.

Arshamian, A., Manko, P., \& Majid, A. (2020). Limitations in odour simulation may originate from differential sensory embodiment. Philosophical Transactions of the Royal Society B, 375(1800).

Barsalou, L.W. (1999) Language comprehension: Archival memory or preparation for situated action? Discourse Processes, 28(1), 61-80.

Barsalou, L. W. (2008). Grounded cognition. Annu. Rev. Psychol., 59, 617-645.

Berkovits, I., Hancock, G. R., \& Nevitt, J. (2000). Bootstrap resampling approaches for repeated measure designs: Relative robustness to sphericity and normality violations. Educational and Psychological Measurement, 60(6), 877-892.

Bergen, B. K., Lindsay, S., Matlock, T., \& Narayanan, S. (2007). Spatial and linguistic aspects of visual imagery in sentence comprehension. Cognitive science, 31(5), 733-764.

Boesveldt, S., \& De Graaf, K. (2017). The differential role of smell and taste for eating behavior. Perception, 46(3-4), 307-319.

Boesveldt, S., Bobowski, N., McCrickerd, K., Maître, I., Sulmont-Rossé, C., \& Forde, C. G. (2018). The changing role of the senses in food choice and food intake across the lifespan. Food Quality and Preference, 68, 80-89.

Boesveldt, S., \& Parma, V. (2021). The importance of the olfactory system in human well-being, through nutrition and social behavior. Cell and Tissue Research, 1-9.

Boulenger, V., Hauk, O., \& Pulvermüller, F. (2009). Grasping ideas with the motor system: semantic somatotopy in idiom comprehension. Cereb Cortex, 19(8),1905-1914.

Brysbaert, M., Warriner, A.B., \& Kuperman, V. (2014). Concreteness ratings for 40 thousand generally known English word lemmas. Behavior research methods, 46(3), 904-911.

Castaño, E., \& Carrol, G. (2020). Mental Simulation in the Processing of Literal and Metaphorical Motion Language: An Eye Movement Study. Metaphor and Symbol, 35(3), 153-170.

Clark, J.E. (1998). Taste and flavour: their importance in food choice and acceptance. Proceedings of the Nutrition Society, 57, 639-643. 
Creusen, M. E., \& Schoormans, J. P. (2005). The different roles of product appearance in consumer choice. Journal of product innovation management, 22(1), 63-81.

Croijmans, I., Hendrickx, I., Lefever, E., Majid, A., \& Van Den Bosch, A. (2020). Uncovering the language of wine experts. Natural Language Engineering, 26(5), 511-530.

Croijmans, I., \& Majid, A. (2016). Not all flavor expertise is equal: The language of wine and coffee experts. PloS One, 11(6).

Croijmans, I., Speed, L.J., Arshamian, A., \& Majid, A. (2019). Measuring multisensory imagery of wine: The vividness of wine imagery questionnaire. Multisensory Research, 32(3), 179-195.

Croijmans, I., Speed, L.J., Arshamian, A., \& Majid, A. (2020). Expertise shapes multimodal imagery for wine. Cognitive science, 44(5).

Croijmans, I., \& Wang, Q. J. (2021). Do you want a description with that wine? The role of wine mental imagery in consumer's desire to drink using the revised Vividness of Wine Imagery Questionnaire (VWIQ-II). Journal of Sensory Studies, e12712.

Danner, L., Johnson, T.E., Ristic, R., Meiselman, H.L., \& Bastian, S.E. (2017). "I like the sound of that!" Wine descriptions influence consumers' expectations, liking, emotions and willingness to pay for Australian white wines. Food Research International, 99, 263-274.

Elder, R.S., \& Krishna, A. (2010). The effects of advertising copy on sensory thoughts and perceived taste. Journal of Consumer Research, 36, 748-756.

Fenko, A., De Vries, R., \& Van Rompay, T. (2018). How strong is your coffee? The influence of visual metaphors and textual claims on consumers' flavor perception and product evaluation. Frontiers in psychology, 9, 53.

Gilbert, A. N., Crouch, M., \& Kemp, S. E. (1998). Olfactory and visual mental imagery. Journal of Mental Imagery, 22(3-4), 137-146.

Glucksberg, S. (2003). The psycholinguistics of metaphor. Trends in cognitive sciences, 7(2), 92-96. Grosch, W. (1998). Flavour of coffee: A review. Nahrung, 42, 344-350.

Herdenstam, A.P., Hammarén, M., Ahlström, R., \& Wiktorsson, P.A. (2009). The professional language of wine: Perception, training and dialogue. Journal of Wine Research, 20(1), 53-84.

The jamovi project (2021). jamovi. (Version 2.2) [Computer Software]. Retrieved from https://www.jamovi.org.

Johnson, T.E., \& Bastian, S.E. (2007). A preliminary study of the relationship between Australian wine consumers' wine expertise and their wine purchasing and consumption behaviour. Australian Journal of Grape and Wine Research, 13(3), 186-197.

Jürkenbeck, K., \& Spiller, A. (2021). Importance of sensory quality signals in consumers' food choice. Food Quality and Preference, 90, 104155. 
Krishna, A, (2012). An integrative review of sensory marketing: Engaging the senses to affect perception, judgment and behavior. Journal of Consumer Psychology, 22(3), 332-351.

Krishna, A., Cian, L., \& Sokolova, T. (2016). The power of sensory marketing in advertising. Current Opinion in Psychology, 10, 142-147.

Krishna, A., \& Schwarz, N. (2014). Sensory marketing, embodiment, and grounded cognition: A review and introduction. Journal of Consumer Psychology, 24(2), 159-168.

Li, J., Streletskaya, N. A., \& Gómez, M. I. (2019). Does taste sensitivity matter? The effect of coffee sensory tasting information and taste sensitivity on consumer preferences. Food Quality and Preference, 71, 447-451.

Majid, A., \& Burenhult, N. (2014). Odors are expressible in language, as long as you speak the right language. Cognition, 130(2), 266-270.

Majid, A., Roberts, S.G., Cilissen, L., Emmorey, K., Nicodemus, B., O’Grady, L., Woll, B., LeLan, B., De Sousa, H., Cansler, B.L., Shayan, S., De Vos, C., Senft, G., Enfield, N.J., Razak, R.A., Fedden, S., Tufvesson, S., Dingemanse, M., Ozturk, O., ... \& Levinson, S.C. (2018). Differential coding of perception in the world's languages. Proceedings of the National Academy of Sciences, 115(45), 11369-11376.

Marks, D. F. (1973). Visual imagery differences in the recall of pictures. British journal of Psychology, 64(1), 17-24.

Meteyard, L., Cuadrado, S.R., Bahrami, B., \& Vigliocco, G. (2012). Coming of age: A review of embodiment and the neuroscience of semantics. Cortex, 48(7), 788-804.

Muñoz-Vilches, N. C., van Trijp, H. C., \& Piqueras-Fiszman, B. (2020). Tell me what you imagine and I will tell you what you want: The effects of mental simulation on desire and food choice. Food Quality and Preference, 83, 103892.

Papies, E. K. (2013). Tempting food words activate eating simulations. Frontiers in Psychology, 4, Article 838.

Papies, E.K., Barsalou, L.W., \& Rusz, D. (2020). Understanding Desire for Food and Drink: A Grounded-Cognition Approach. Current Directions in Psychological Science, 29(2), 193-198.

Paradis, C., \& Eeg-Olofsson, M. (2013). Describing sensory experience: The genre of wine reviews. Metaphor and Symbol, 28(1), 22-40.

R Core Team (2021). R: A Language and environment for statistical computing. (Version 4.0) [Computer software]. Retrieved from https://cran.r-project.org. (R packages retrieved from MRAN snapshot 2021-04-01).

Ribeiro, T., Corsi, A., Lockshin, L., Louviere, J., \& Loose, S.M. (2020). Analysis of consumer preferences for information and expert opinion using a discrete choice experiment. Portuguese Economic Journal, 19, 67-80. 
654

655

656

657

658

659

660

661

662

663

664

665

666

667

668

669

670

671

672

673

674

675

676

677

678

679

680

681

682

683

684

685

686

687

688

689

690

Schifferstein, H.N., Fenko, A., Desmet, P.M., Labbe, D., \& Martin, N. (2013). Influence of package design on the dynamics of multisensory and emotional food experience. Food Quality and Preference, 27(1), 18-25.

Simonsen, H.G., Lind, M., Hansen, P., Holm, E., \& Mevik, B.H. (2013). Imageability of Norwegian nouns, verbs and adjectives in a cross-linguistic perspective. Clinical linguistics \& phonetics, 27(6-7), 435-446.

Speed, L.J., \& Brysbaert, M. (2020). Dutch Sensory Modality Norms. PsyArXiv [Preprint].

Speed, L.J., \& Majid, A. (2017). Dutch modality exclusivity norms: Simulating perceptual modality in space. Behavior research methods, 49(6), 2204-2218.

Speed, L.J., \& Majid, A. (2020). Grounding language in the neglected senses of touch, taste, and smell, Cognitive Neuropsychology, 37:5-6, 363-392.

Speed, L., Papies, E.K., \& Majid, A. (2021). The role of mental simulation in food attractiveness. PsyArXiv [Preprint]. https://psyarxiv.com/pdw67/

Spencer, M., Sage, E., Velez, M., \& Guinard, J.X. (2016). Using single free sorting and multivariate exploratory methods to design a new coffee taster's flavor wheel. Journal of Food Science, 81(12), 2997-3005.

Suárez-Toste, E. (2007). Metaphor inside the wine cellar: On the ubiquity of personification schemas in winespeak. Metaphorik. de, 12(1), 53-64.

Suárez-Toste, E. (2017). Babel of the senses: On the roles of metaphor and synesthesia in wine reviews. Terminology. International Journal of Theoretical and Applied Issues in Specialized Communication, 23(1), 89-112.

Turnwald, B.P., Crum, A.J. (2019). Smart food policy for healthy food labeling: Leading with taste, not healthiness, to shift consumption and enjoyment of healthy foods. Preventive Medicine, 119, 7-13.

Willett, W., Rockström, J., Loken, B., Springmann, M., Lang, T., Vermeulen, S., ... \& Murray, C. J. (2019). Food in the Anthropocene: the EAT-Lancet Commission on healthy diets from sustainable food systems. The Lancet, 393(10170), 447-492.

Wyrwa, J., \& Barska, A. (2017). Packaging as a source of information about food products. Procedia Engineering, 182, 770-779. 


\section{Appendix A: Screenshot Survey}

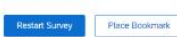

Oumintimin

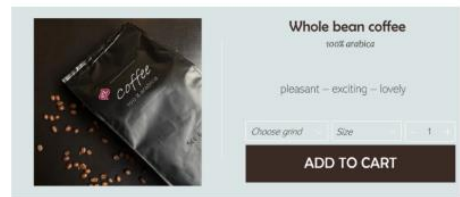

Can you imagine the flavour of this coffee?

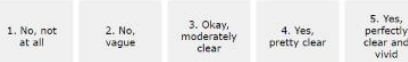

Would you like to try this coffee?

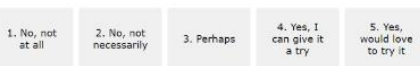

How much are you willing to pay for a bag of 500 grams of this coffee? Answer
in $\boldsymbol{\varepsilon}(\$ 1=\{0.72 / \epsilon 1=\varepsilon 0.86)$.

Shortened and adjusted version of the Vividness of Wine Imagery Questionnaire (VWIQ, Croijmans,

Speed, Arshamian \& Majid, 2019).

The following part contains two scenarios. In both scenarios, you will be given a description of a scene

followed by three statements related to the scenario given. After reading the statements, please close your eyes to construct a mental image of the described object or scene. Once your image of this scene has been formed, open your eyes to rate the mental image you constructed. You will do this for each different scenario-based mental image requested, and are then asked to rate how vivid several aspects of the image are.

1. No image at all (only 'knowing' that you are thinking of the object)

2. Vague and dim

3. Moderately clear and vivid

4. Clear and reasonably vivid

5. Perfectly clear and as vivid as the real situation

A. It is early in the morning. You just got out of bed, and start the day with a pour-over coffee.

- The smell that is released when you pour hot water over the filter with ground coffee

- The warmth as you wrap your hands around the cup of coffee

- The taste of the coffee when you have your first sip 
B. You ordered an espresso in your favourite specialty coffee bare, and are waiting for the barista to hand you the espresso.

- The smell of freshly ground coffee beans

- The mouthfeel of the espresso when you have your first sip

- The taste that remains when you have finished the drink 


\section{Appendix C: Self-Reported Expertise Questionnaire}

Based on the Self-reported Wine Expertise Questionnaire (Johnson \& Bastian, 2007)

These statements are about your subjective expertise regarding coffee. Please rate them as how much you agree with these $(1=$ strongly disagree, $9=$ strongly agree $)$.

- I am knowledgeable about coffee

- I do not feel very knowledgeable about coffee

- Among my circle of friends, I'm one of the experts on coffee

- Compared to other people, I know less about coffee

- When it comes to coffee, I really don't know a lot 